\title{
In vitro Salt Tolerance of Safflower (Carthamus tinctorius L.) Genotypes using Different Explants
}

\author{
Mahdi Hamedi, Pooran Golkar ${ }^{*}$ and Ahmad Arzani \\ Department of Agronomy and Plant Breeding, College of Agriculture, Isfahan \\ University of Technology, Isfahan 8415683111, Iran
}

Key words: Cellular level, Salt tolerance, Carthamus tinctorius

\begin{abstract}
To evaluate the response of different genotypes of safflower (Carthamus tinctorius L.) to in vitro salt stress was conducted. Callus derived from leaflet, pedicel, hypocotyls, and adaxial and abaxial surfaces of the leaf were subjected to in vitro salt stress at 0,100 and $200 \mathrm{mM}$ of $\mathrm{NaCl}$. The relative growth rate (RGR), callus growth rate (CGR), relative water content (RWC), tolerance index (TOL) and necrosis percentage were assessed. Results of analysis of variance indicated significant effects of salt stress, significant differences among genotypes for all traits and significant genotype $\times$ salt stress interaction for CGR, RWC and necrosis traits. The application of $\mathrm{NaCl}$ decreased RGR, CGR, RWC and TOL, significantly, while a significant increase observed across all the tested explants and genotypes for necrosis percentage data. An Iranian safflower genotype (K21) superior for RGR, RWC and TOL was the most salt tolerant genotype at the cellular level.
\end{abstract}

\section{Introduction}

Salinity is a major factor limiting the crop productivity in arid and semi-arid regions of the world (Altman 2003, Ashraf and Foolad 2013, Hasegwa 2013). Breeding and selection strategies to improve salt tolerance of crop plants are important measures to increase crop productivity (Rai et al. 2011). The major inhibitory effect of salinity upon plant growth has been attributed to osmotic stress ion toxicity and nutrient imbalance (Zhu 2007). The combined effects of these stresses could lead to a metabolic imbalance, resulting in oxidative stress. Physiological mechanisms of salt tolerance at cellular level are complex and not

*Author for correspondence: <golkar@cc.iut.ac.ir>. ${ }^{1}$ Research Institute for Biotechnology and Bioengineering, Isfahan University of Technology, Isfahan-8415683111, Iran. 
yet fully understood. Due to these reasons, breeding crop plants for salt tolerance has been difficult and slow (Arzani 2008). Plant species usually exhibit variation in salt tolerance at the whole plant and cellular level (Hasegwa 2013).

In vitro selection technique has been used to improve abiotic stresses such as cold hardiness, salt tolerance and drought tolerance (Zair et al. 2003, Bajji et al. 2004, Gawande et al. 2005). In vitro procedures provide a promising and feasible approach to develop salt tolerance plants (Arzani and Mirodjagh 1999, Chawla 2000, Hasan and Sarker 2013). In vitro physiological traits provide the basis for efficient germplasm screening procedures for salinity tolerance (Lutts 2004). This method is based on the induction of genetic variation among cells, tissues or regenerated plants (Gandonou et al. 2005, Rai et al. 2011) The plant cell culture studies also allow isolation and selection of salt and drought tolerant lines to elucidate mechanism of tolerance operating at cellular level (Bajji et al. 1998). Genetic manipulation and selection of favorable variant strains are supplementary tools to traditional breeding for production of stress-resistant plants (Borsani et al. 2003, Ashraf and Foolad 2013) at in vitro condition. Houshmand et al. (2005) compared in vitro screening with field screening method and reported that in vitro screening was comparably successful in recognizing salt-tolerant genotypes in durum wheat.

In vitro selection of salt tolerant cell lines has been reported in several species such as wheat (Barakat and Abdel-latif 1996, Golkar et al. 2007), durum wheat (Arzani and Mirodjagh 1996), rice (Lutts et al. 1999, Basu et al. 2002, Hasan and Sarker 2013), sunflower (Alvarez et al. 2003), sugarcane (Gandonou et al. 2005, Errabii et al. 2007), fennel (Khorami and Safarnejad 2011) and potato (Sabbah and Tal, 1990). All of which consistently suggest that tissue culture could be used as a tool to improve salt tolerance in crop plants.

Safflower (Carthamus tinctorius L.) is an oilseed crop having good quality oil (Knowles 1989, Weiss 2000). Safflower is a multi-purpose crop with moderate salt-tolerance and long roots that contribute to its adaptation to the dry and marginal areas (Weiss 2000, Golkar 2014). Although classic breeding implemented to the high yield safflower cultivars, but in vitro technology could be an implement to screen tolerant genotypes to environmental stresses (Rai et al. 2011). To date, in vitro studies have only been performed to assess drought tolerance in safflower (Zebarjadi et al. 2010). Therefore in vitro salt tolerance assessment in safflower is still lacking. In addition, the majority of tissue culture works in safflower are devoted to optimize direct plant regeneration (Baker 1996, Dilek et al. 2008) rather than developing salinity tolerant genotypes.

The objectives of the present study were: (i) to assess the safflower explants for callus production and obtaining the most suitable explant for in vitro study 
and (ii) to assess in vitro salt tolerance of a geographically diverse set of safflower genotypes. The safflower genotypes that display an increased tolerance to in vitro salt-stress could be an important genetic material for salt stress improvement at the whole plant level.

\section{Materials and Methods}

The experiment was conducted at Tissue Culture Laboratory of Institute of Biotechnology and Bioengineering at Isfahan University of Technology in 2014. Twenty genotypes of safflower with native and exotic origin were used. This experiment was carried out as a factorial based on a completely randomized design with five replications. Seeds were surface sterilized for 15 min in 1.5\% sodium hypochlorite, then rinsed three times with sterilized distilled water. After disinfection, the seeds were incubated on MS supplemented with $30 \mathrm{~g} / \mathrm{l}$ sucrose and solidified with $8 \mathrm{~g} / \mathrm{l}$ agar. The medium was adjusted to $\mathrm{pH} 5.7$ before autoclaving at $121^{\circ} \mathrm{C}$ for $30 \mathrm{~min}$. The cultures were incubated in growth chamber with 8/16 light/dark cycle at temperature $24^{\circ} \mathrm{C}$. After 7 - 10 days, germinated seeds on were used to dissect different explants.

Various explants comprising of hypocotyls (2 - $3 \mathrm{~mm}$ long), leaflet, pedicle, adaxial (upper) and abaxial (lower) segments of the leaf were used in this study. The MS (Duchefa, Haarlem, The Netherlands) supplemented with $30 \mathrm{~g} / \mathrm{l}$ sucrose and $8 \mathrm{~g} / \mathrm{l}$ agar, $2 \mathrm{mg} / 1$ 2, 4-D and $0.1 \mathrm{mg} / \mathrm{l} \mathrm{Kn}$ was used. The cultures incubated in a dark culture room at $24^{\circ} \mathrm{C}$. After 4 weeks of incubation, the induced calli were transferred to the MS to which various concentrations of 0,100 and $200 \mathrm{mM}$ $\mathrm{NaCl}(0,0.6$ and $1.2 \% \mathrm{NaCl}(\mathrm{w} / \mathrm{v}))$ were added. The incubation period in salt stress lasted 16 days. After 16 days of salt treatment, relative growth rate (RGR), callus growth rate (CGR), relative water content (RWC), and callus chlorosis were measured and tolerance index (TOL) was calculated.

RGR of callus was calculated as $\left(\mathrm{W}_{1}-\mathrm{W}_{0}\right) / \mathrm{W}_{0} \times 100$, where $\mathrm{W}_{0}$ is the initial callus weight and $W_{1}$ was considered as the final weight of calli after 16 days of salt treatment (Errabi et al. 2007).

The relative water content (RWC) is a parameter reflecting cellular osmotic stress. Callus samples of known fresh weight were dried in an oven set at $65^{\circ} \mathrm{C}$ for $48 \mathrm{hrs}$ to calculate callus dry weight. After which they were re-weighed and the difference in the initial and final mass determined. Relative water content was calculated as [(callus fresh weight - callus dry weight)/callus dry weight $\times$ 100]. 
The callus growth rate (CGR) was calculated by the mean of callus growth rate $(\mathrm{mm} /$ day) at 0,8 and 16 days after callus transform to salinity stress. The callus diameter (di) was calculated by root square of (callus length $\times$ callus width) (Compton, 1994). It should be noted that callus diameter in each time ( $\mathrm{d}_{0}, \mathrm{~d} 8$ and d16) was calculated by the difference between callus diameter at each time from previous time.

Callus chlorosis was determined visually as percentage of necrotic callus, 16 days after moving callus to the salt containing medium. Tolerance index (TOL) was calculated as RGR (treatment)/RGR (control) (Zebarjadi et al. 2010). Salt tolerance response of 20 geographically diverse genotypes of safflower was determined using only hypocotyl explant following a procedure described above.

Prior to the analysis of variance (ANOVA), the data were tested for normal distribution with the Kolmogorov-Smirnov test. The non-normal variables were transformed where appropriate by Arcsin X. The data were subjected to ANOVA using PROC GLM of SAS version 9.3 (SAS Institute, 2011). Then, mean comparisons were carried out using Fisher's least significant difference (LSD $5 \%$ ) test. The biplot was constructed by representing the genotypes as points and the traits as vectors from the origin to the position of the trait in the biplot using GGE biplot software (Yan 2001). A GGE biplot was generated based on the genotype-by-environment table of yield using GGE biplot software (Yan 2001).

\section{Results and Discussion}

The results of analysis of variance showed that there was significant difference between explants and salinity treatments for RGR, CGR, RWC, Chl and TOL (data not shown). The explant $\times$ salinity interaction was only significant for chlorosis. Mean comparisons of traits for different explants showed that the highest value for RGR (1.28) was denoted to leaflet (Table 1). The highest value for RWC (16.15) and CGR (0.15) was observed at abaxial part of the leaf (Table 1). Also the highest (0.74) and the least (0.07) values of TOL and chlorosis were found to belong to hypocotyls, respectively (Table 1). Results of the ANOVA indicated significant difference among the genotypes for all traits (Table 2). This result indicated that there is genetic variation among the genotypes for in vitro salt tolerance. Salt treatments affected all traits including RGR, CGR, RWC, chlorosis and TOL (Table 2). Previously, significant genotypic variation for chlorosis and RGR was reported in other crops such as durum wheat (Arzani and Mirodjagh 1996). The salt-stress $\times$ genotype interaction was significant for CGR, RWC and cholorosis (Table 2). 
The RGR, CGR, RWC and TOL of calli were significantly reduced with increase in salt levels (data not shown). Although the calli at $100 \mathrm{mM} \mathrm{NaCl}$ treatment showed the highest growth rate among the salt treatments, the lowest RGR, CGR and RWC was observed at $200 \mathrm{mM} \mathrm{NaCl}$ treatment. The CGR was found to reduce with increase of salt concentrations. This finding is in agreement with that in rice (Khaleda et al. 2007) and cotton (Ashraf and Ahmad 2000).

Table 1. Mean comparisons for callus-related traits studied under in vitro salt stress in safflower.

\begin{tabular}{llllll}
\hline \multirow{2}{*}{ Explants } & \multicolumn{5}{l}{ Studied traits } \\
\cline { 2 - 6 } & RGR & CGR & RWC & Chl & TOL $^{*}$ \\
\hline Leaflet & $0.752^{\mathrm{ab}}$ & $-0.002^{\mathrm{bc}}$ & $11.06^{\mathrm{c}}$ & $0.23^{\mathrm{a}}$ & $0.49^{\mathrm{a}}$ \\
Abaxial (leaf) & $0.39^{\mathrm{b}}$ & $0.15^{\mathrm{a}}$ & $16.15^{\mathrm{a}}$ & $0.07^{\mathrm{b}}$ & $0.28^{\mathrm{c}}$ \\
Adaxial (leaf) & $1.18^{\mathrm{b}}$ & $-0.03^{\mathrm{c}}$ & $14.06^{\mathrm{b}}$ & $0.17^{\mathrm{a}}$ & $0.47^{\mathrm{b}}$ \\
Pedicle & $1.28^{\mathrm{a}}$ & $0.1 \mathrm{a}^{\mathrm{b}}$ & $12.92^{\mathrm{bc}}$ & $0.074^{\mathrm{b}}$ & $0.44^{\mathrm{bc}}$ \\
Hypocotyl & $0.76 \mathrm{a}^{\mathrm{b}}$ & $0.01^{\mathrm{bc}}$ & $110.06^{\mathrm{c}}$ & $0.07^{\mathrm{b}}$ & $0.74^{\mathrm{a}}$ \\
\hline
\end{tabular}

Means in each column followed by the similar letters not significantly differ at $\mathrm{p}<0.01$. *RGR: Relative growth rate, CGR: Callus growth rate, RWC: Relative water content, Chl: Chlorosis, TOL: Tolerance index.

Table 2. Results of analysis of variance for callus related traits of safflower genotypes subjected to salt stress.

\begin{tabular}{lllllll}
\hline \multirow{2}{*}{$\begin{array}{l}\text { Source of } \\
\text { variation }\end{array}$} & $\mathrm{df}$ & \multicolumn{5}{c}{ Mean squares } \\
\cline { 3 - 7 } & & RGR & CGR & RWC & Chl & TOL $^{*}$ \\
\hline Genotype (G) & 19 & $0.216^{* *}$ & $0.93^{* *}$ & $673.8^{* *}$ & $0.09^{* *}$ & $0.20^{* *}$ \\
Salt stress (S) & 2 & $4.04^{* *}$ & $21.28^{* *}$ & $6633^{* *}$ & $5.54^{* *}$ & $2.69^{* *}$ \\
G $\times$ S & 38 & $0.03^{\mathrm{ns}}$ & $0.31^{* *}$ & $221.4^{* *}$ & $0.07^{* *}$ & $0.03^{\mathrm{ns}}$ \\
Residual & 240 & 0.027 & 0.14 & 71.72 & 0.02 & 0.03 \\
\hline
\end{tabular}

ns, *and **: Non significant, significant at 1 and $5 \%$ probability levels, respectively. ${ }^{*}$ RGR: Relative growth rate, CGR: Callus growth rate, RWC: Relative water content, Chl: Chlorosis, TOL: Tolerance index.

Increase in salt concentration also caused the reduction of osmotic potential of the medium. This could be explained due to the requirement for maintaining turgor of the growing cells, which consumes energy and eventually leads to a decrease in callus growth. Increase in osmotic stress by $\mathrm{NaCl}$ application was accompanied by steep decline in moisture content of tissues (Liu et al. 2006). Likewise, Khaleda et al. (2007) also reported the decreasing trend in callus proliferation and plant regeneration with the increasing concentrations of $\mathrm{NaCl}$ in rice. Barakat and Abdel-latif (1996) studied in vitro drought stress and found that increase in poly ethylene glycol, as a drought stress agent, reduces callus 
growth rate and relative water content of durum wheat calli. In another study, in vitro drought stress has diminished RWC and RGR in safflower calli (Zebarjadi et al. 2010). It has been established that the water potential gradient between the cells and the nutrient medium caused by $\mathrm{NaCl}$ results in dehydration of the cells and reduction of fresh weight in calli (Khaleda et al. 2007).

The results of the current study indicated that the relative growth rate inhibition might be due to reduction in water availability of cells and the losses of turgor pressure, which also was previously reported due to drought stress in some crop species such as Carthamus tinctorius (Zebarjadi et al. 2010), Triticum durum (Bajji et al. 2000, Lutts et al. 2004), Oryza sativa (Lutts et al. 1996), and Saccharum sp. (Errabi et al. 2007). Similar to these results, Rafiq et al. (2008) reported that the fresh and the dry weight of mungbean decreased with increase in concentration of $\mathrm{NaCl}$. Increasing salinity stress was synchronized with a reduction in TOL index for safflower calli. This result is consistent with previous reports on drought stress in safflower (Zebarjadi et al. 2010). The assessment of callus at the amount of salt injury reflected in partial or complete chlorosis in salt sensitive genotypes. An increase of cholorosis percentage was observed with increase of salinity concentrations (Table 2). This result is consistence with that of Karadimova and Djambova (1993) and Arzani and Mirodjagh (1999) who also observed that increasing $\mathrm{NaCl}$ level caused higher brown coloration and apparent necrosis in wheat. However, their speculation in wheat is supported by the present results that chlorosis could be used as a criterion to screen in vitro salt tolerant in safflower genotypes as well.

Mean comparisons of safflower genotypes for their response to salt stress are presented in Table 3. The highest value for RGR (0.82) RWC (35.56) and TOL $(0.82)$ belonged to $K_{21}$. This genotype of $K_{21}$ seemed to maintain a higher RWC under $\mathrm{NaCl}$-induced salt stress resulting in a higher growth rate. The highest value of CGR (0.55) and the least value of chlorosis (0.09) were observed in Mex. 6 - 97 (Table 3). Genotypes C4110, ISF $14, A_{2}$, IL.111, Arka2811, Mex.17-45, Hartman, PI-250190 and PI-301055 showed negative CGR at 100 and $200 \mathrm{Mm} \mathrm{NaCl}$. The genotype of GE-62918 showed the least amount of RGR (0.42) and TOL (0.3) whilst it possessed the highest chlorosis (0.39) (Table 3). Therefore, $\mathrm{K}_{21}$ and Mex. 6-97 were the most salt-tolerant under in vitro conditions. On the other hand, genotype of GE-62918 was the least salt tolerant under in vitro conditions. These results imply that callus growth and related-traits under salt stress are a genotypic dependent phenomenon that is in agreement with the data reported in mungbean (Rafiq et al. 2008), sugarcane (Errabii et al. 2007) and wheat (Arzani and Mirodjagh 1999). The mechanisms of $\mathrm{NaCl}$ tolerance might, however, be quite varied depending on plant species (Lutts et al. 2004). The physiological 
mechanisms operating at plant cell level in response to salt-stress in safflower genotypes may be different from that of other crops and deserve further research.

Table 3. Mean comparisons of safflower genotypes assessed for in vitro related salttolerance traits.

\begin{tabular}{|c|c|c|c|c|c|c|c|}
\hline Genotype & Code & Origin & RGR & CGR & RWC & Chl & $\mathrm{TOL}^{*}$ \\
\hline AC-sunset & 1 & Canada & $0.57 \mathrm{~cd}$ & $-0.051^{f-i}$ & $14.8^{\text {e-h }}$ & $0.24^{\mathrm{b}-\mathrm{h}}$ & 0.54 efg \\
\hline GE-62918 & 2 & Germany & $0.42 \mathrm{e}$ & -0.177 ghi & $27.03^{b}$ & $0.39^{a}$ & $0.3^{i}$ \\
\hline $\mathrm{C}_{111}$ & 3 & Isfahan, Iran & $0.74^{\mathrm{ab}}$ & $0.29^{a-d}$ & $18.87^{\mathrm{c}-\mathrm{f}}$ & $0.34^{\mathrm{ab}}$ & $0.69^{\text {a-e }}$ \\
\hline $\mathrm{C}_{4110}$ & 4 & Isfahan, Iran & $0.67 \mathrm{bc}$ & $0.19 \mathrm{c-f}$ & $13.85^{\text {e-h }}$ & $0.15^{\text {hij }}$ & $0.78 \mathrm{ab}$ \\
\hline ISF-14 & 5 & Isfahan, Iran & $0.68 \mathrm{bc}$ & $-0.28^{i}$ & $15.91^{\text {e-h }}$ & $0.29 \mathrm{~b}-\mathrm{f}$ & $0.56^{\text {efg }}$ \\
\hline $\mathrm{A}_{2}$ & 6 & Tabriz, Iran & $0.54^{\mathrm{d}}$ & $0.22^{b-f}$ & $12.94 \mathrm{fgh}$ & $0.11 \mathrm{ij}$ & $0.51 \mathrm{fgh}$ \\
\hline $\mathrm{K}_{21}$ & 7 & Sanandaj, Iran & $0.82^{a}$ & $0.29^{a-d}$ & $35.56^{\mathrm{a}}$ & $0.19^{\mathrm{f}-\mathrm{j}}$ & $0.82^{a}$ \\
\hline ISF-28 & 8 & Isfahan, Iran & $0.75^{a b}$ & $0.23^{\text {b-e }}$ & $22.2 \mathrm{bcd}$ & $0.3^{a-e}$ & $0.78^{a b}$ \\
\hline IL-111 & 9 & Orumieh, Iran & $0.48^{\text {ed }}$ & $0.051^{\mathrm{d}-\mathrm{h}}$ & $12.34^{\mathrm{h}}$ & $0.26^{b-g}$ & $0.68^{a-e}$ \\
\hline Arak-2811 & 10 & Arak, Iran & 0.53 de & -0.193 hi & $11.01^{\mathrm{h}}$ & $0.32 \mathrm{abc}$ & $0.37 \mathrm{hi}$ \\
\hline Mex.7-38 & 11 & Mexico & $0.69^{b}$ & $0.47^{a b}$ & $26.02^{b}$ & $0.34^{\mathrm{ab}}$ & $0.8^{\mathrm{a}}$ \\
\hline Mex.2-138 & 12 & Mexico & $0.5^{\mathrm{ed}}$ & $0.41^{a b c}$ & $26.15^{b}$ & $0.32^{\mathrm{a}-\mathrm{d}}$ & 0.45 ghi \\
\hline Mex.22-191 & 13 & Mexico & $0.48^{\text {ed }}$ & $0.26^{b-e}$ & $18.44^{\mathrm{d}-\mathrm{g}}$ & $0.22^{\mathrm{e}-\mathrm{i}}$ & $0.59^{\mathrm{d}-\mathrm{g}}$ \\
\hline Mex.13-216 & 14 & Mexico & $0.5^{\text {ed }}$ & $0.48^{a b}$ & $22.64 \mathrm{bcd}$ & $0.22^{\mathrm{d}-\mathrm{h}}$ & $0.55^{\text {efg }}$ \\
\hline Mex.17-45 & 15 & Mexico & 0.52 de & $0.085^{\mathrm{d}-\mathrm{g}}$ & $27.4^{\mathrm{b}}$ & $0.23^{\mathrm{c}-\mathrm{h}}$ & 0.54 efg \\
\hline Mex.6-97 & 16 & Mexico & 0.52 de & $0.55^{a}$ & 19.14 cde & $0.09 \mathrm{j}$ & $0.61^{c-f}$ \\
\hline Gila & 17 & USA & $0.76^{a b}$ & $0.067 \mathrm{~d}-\mathrm{h}$ & $13.66^{\text {e-h }}$ & $0.26^{b-g}$ & $0.74^{\mathrm{a}-\mathrm{d}}$ \\
\hline Hartman & 18 & USA & $0.72 \mathrm{ab}$ & $-0.015^{\text {e-i }}$ & 24.5 bc & $0.27 \mathrm{~b}-\mathrm{f}$ & $0.76^{a b c}$ \\
\hline PI-250190 & 19 & Pakistan & 0.52 de & -0.121 ghi & $12.71 \mathrm{gh}$ & 0.16 ghij & $0.52^{\text {fgh }}$ \\
\hline PI-301055 & 20 & Turkey & $0.72 \mathrm{bc}$ & $0.47 \mathrm{ab}$ & $13.82^{\text {e-h }}$ & $0.3^{\mathrm{a}-\mathrm{e}}$ & $0.62^{b-f}$ \\
\hline
\end{tabular}

Means in each column, followed by the similar letters are not significantly different at $\mathrm{p}<0.01$. ${ }^{*}$ RGR: Relative growth rate, CGR: Callus growth rate, RWC: Relative water content, Chl: Chlorosis, TOL: Tolerance index.

The "which-won-where" view of the GGE biplot is an effective visual tool in genotype by environment analysis (Yan 2002). The GGE biplot analysis was constructed to show which safflower genotypes yielded the most at control (E1), $100 \mathrm{mM}\left(\mathrm{E}_{2}\right)$ and $200 \mathrm{mM}\left(\mathrm{E}_{3}\right) \mathrm{NaCl}$ environments (Figs 1 - 3). In control environment ( $\left.E_{1}\right)$ the genotypes of $\mathrm{C}_{111}, \mathrm{C}_{4110}$ and $\mathrm{A}_{2}$ showed the best CGR but the GE62918 and PI-250190 had the least value for CGR (Fig. 1). E2 and E3 represented close one another on the biplot, showing that the ranking of genotypes are almost similar at 100 and $200 \mathrm{mM} \mathrm{NaCl}$ treatments for CGR. Therefore, it can be 
deduced that the significant effect of $\mathrm{G} \times \mathrm{E}$ is due to the control $\left(\mathrm{E}_{1}\right)$ and $\mathrm{NaCl}$ treatment interaction ( $\left.\mathrm{E}_{2}+\mathrm{E}_{3}\right)$. Genotype of Mex.6-97 had the highest CGR at both $E_{2}(100 \mathrm{Mm})$ and $\mathrm{E}_{3}(200 \mathrm{mM})$. In addition, Mex.13-216, Mex.2-138, Mex.7-38 and PI-301055 were close to Mex. 6-97 showing almost similar CGR at E2 (100 $\mathrm{mM}$ ) and Ез $(200 \mathrm{mM})$. Therefore, these genotypes were superior for callus growth rate under in vitro salt stress. On the other hand, genotypes ISF-14 and Arak-2811 were inferior for CGR at $E_{3}(200 \mathrm{mM})$ and $\mathrm{E}_{2}(100 \mathrm{mM} \mathrm{NaCl})$.

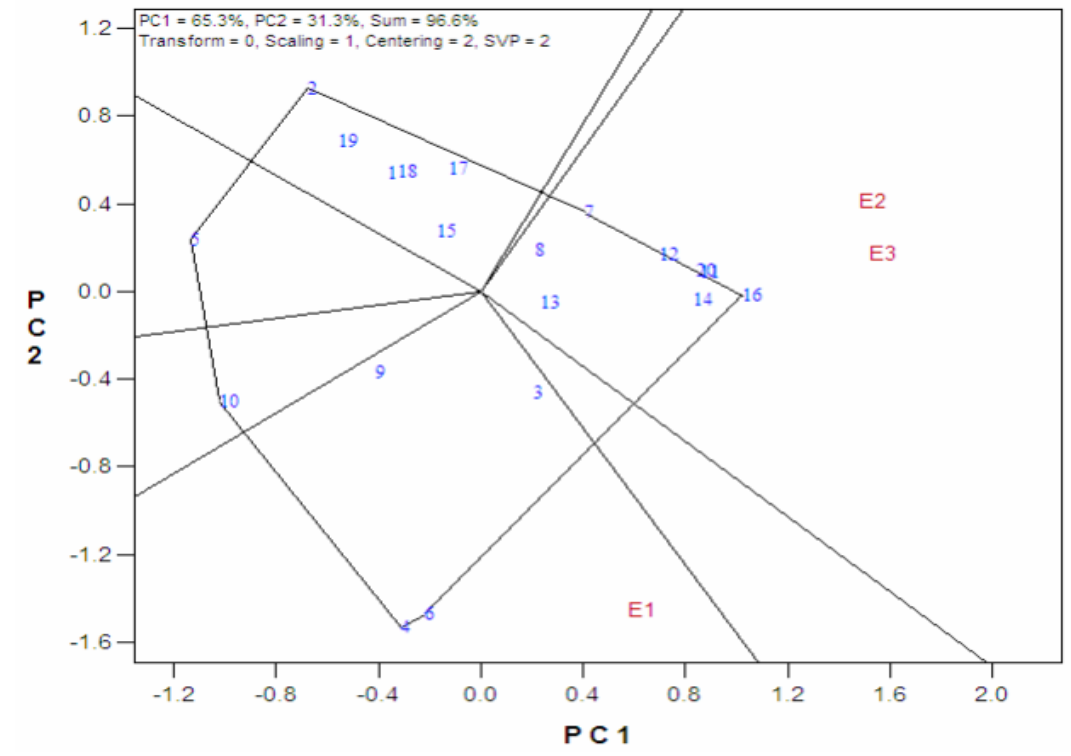

Fig 1. View of the GGE biplot to show which genotypes performed better in which environments for CGR at $\mathrm{E}_{1}$ (control), $\mathrm{E}_{2}(100 \mathrm{mM})$ and $\mathrm{E}_{3}(200 \mathrm{mM} \mathrm{NaCl})$.

The "which-won-where" biplot graph for chlorosis showed that GE-62918 at E2 $(100 \mathrm{Mm})$ and Arak-2811 and Mex.7-38 genotypes at Eз $(200 \mathrm{mM})$ had the highest chlorosis (Fig. 2). Hence, GE-62918, Mex.7-38 and Arak2811 were the most sensitive genotypes to salt stress. On the other hand, Mex.6-97 and PI250190 were the most salt tolerant genotypes having the least chlorosis at both $\mathrm{E}_{2}$ and $\mathrm{E}_{3}$.

The GGE biplot for RWC indicated that $\mathrm{K}_{21}$ had the highest RWC at $\mathrm{E}_{1}$ (control) (Fig. 3). In addition, $\mathrm{GE}_{62918}$, Mex.2-138 and Mex. 17-45 had relatively high RWC at $E_{1}$. Mex.7-38 and Hartman had the highest RWC at both $E_{2}$ and $E_{3}$ (Fig. 3). A2, Arak2811 and PI-30155 had the least value for RWC at all the environments. The superiority of $K_{21}$ at $E_{1}$ could be compromised from genotype stability of $\mathrm{K}_{21}$ at normal environment.

Results of correlation coefficients showed that RGR and TOL strongly correlated $(r=0.93)$. This result indicated that the relative growth rate of calluses 
most highly associated with in vitro salt tolerance. Positive and significant correlation coefficients were observed between RGR with CGR $\left(r=0.64^{* *}\right)$, RWC $\left(\mathrm{r}=0.56^{* *}\right)$ and TOL $\left(\mathrm{r}=0.73^{* *}\right)$. The highest negative correlation $(\mathrm{r}=-0.75)$ was observed between TOL and chlorosis.

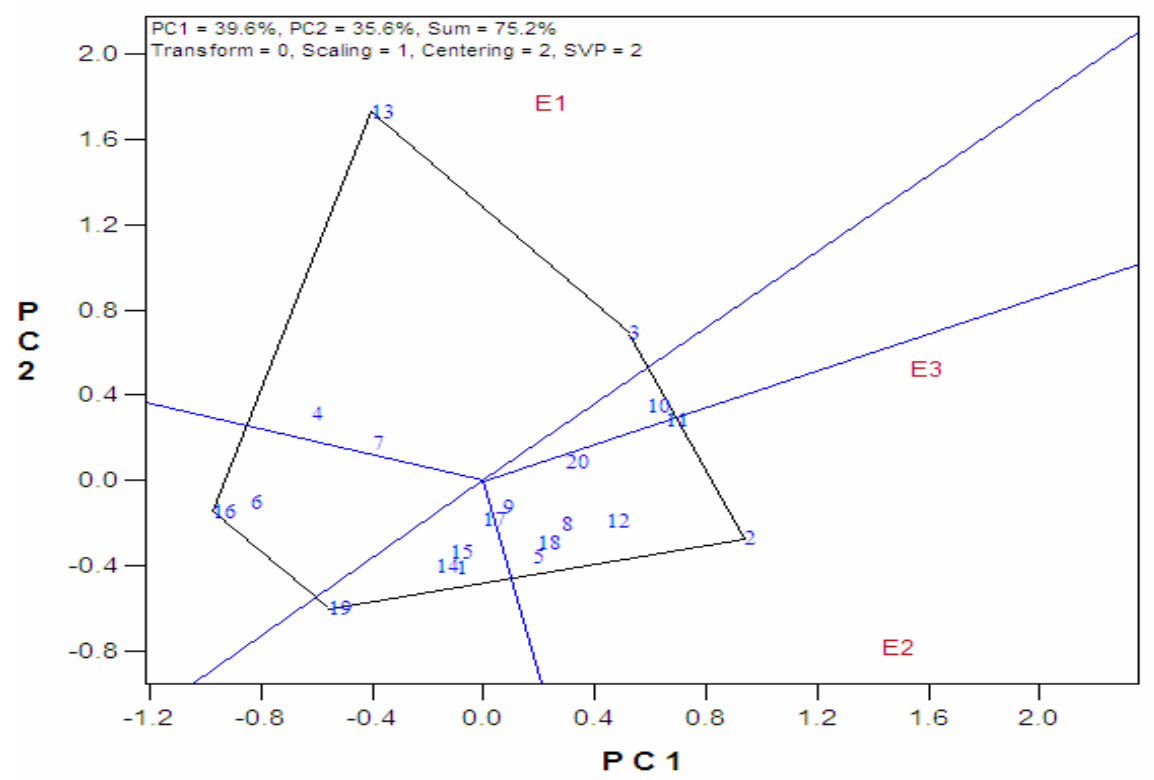

Fig. 2. View of the GGE biplot to show which genotypes performed better in which environments for chlorosis at $E_{1}$ (control), $E_{2}(100 \mathrm{mM})$ and $E_{3}(200 \mathrm{mM})$ of $\mathrm{NaCl}$.

In vitro culture could be used to obtain salt-tolerant plants, assuming that there is a correlation between cellular and in vivo plant responses. The majority of salt tolerance-related processes associated with salt tolerance at the cellular level (Barakat and Abdel-Latif 1996). The physiological mechanisms that operate under salt stress will also ultimately exhibit as the response at the whole plant level (Arzani 2008). Mostly callus cultures are used as an in vitro technique for biochemical and physiological studies in response to salt and water stress at the cellular level (Liu 2006). In the current study, a highly significant variation was observed among the genotypes for in vitro salt tolerance. The hypocotyl explants performed the best for in vitro salt assessment in safflower. Salt stress induced a reduction in RGR, CGR, RWC and TOL and an increase in chlorosis. The overall results suggested that CGR and chlorosis could be used as in vitro selection criteria for screening tolerant genotypes at cellular level. 


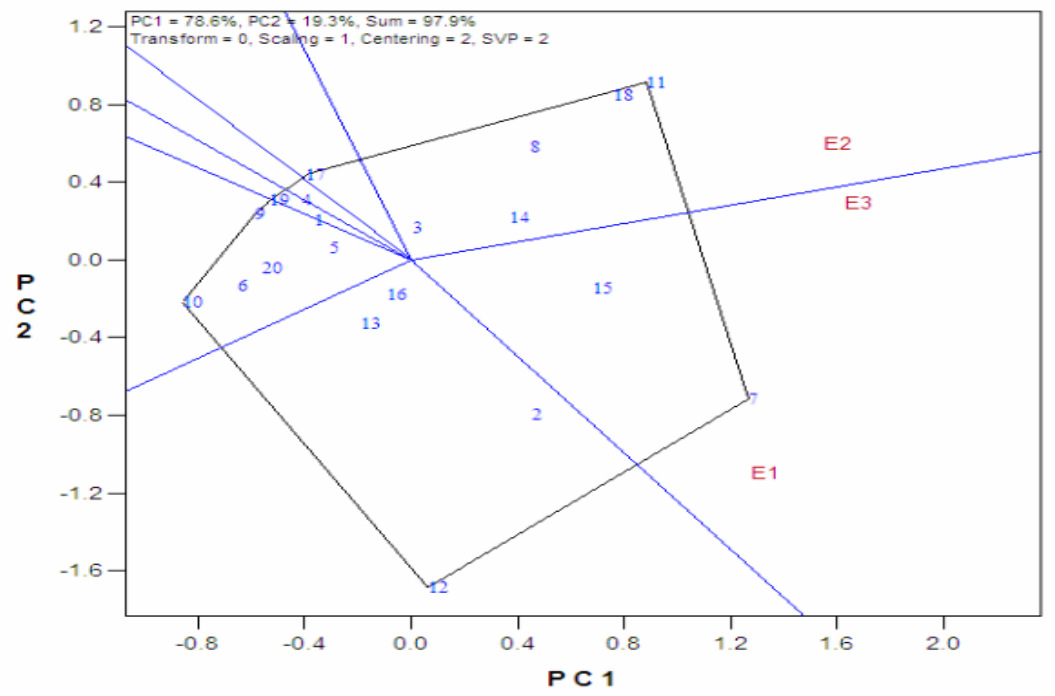

Fig 3. View of the GGE biplot to show which genotypes performed better in which environments for RWC at $E_{1}$ (control), $E_{2}(100 \mathrm{mM})$ and $E_{3}(200 \mathrm{mM})$ of $\mathrm{NaCl}$.

Overall, $\mathrm{K}_{21}$ and Mex.6.97 were the most salt tolerant genotypes under in vitro conditions. On the other hand, GE-62918 and Arak-2811 performed as the most sensitive genotypes to salt stress at cellular level. These genotypes could be used either as parents for breeding at salt tolerance programs or to unravel the biochemical, molecular and physiological mechanisms of $\mathrm{NaCl}$ tolerance at the cellular level.

\section{References}

Altman A (2003) From plant tissue culture to biotechnology: Scientific revolutions, abiotic stress tolerance, and forestry. In Vitro Cell. Dev. Biol. Plant 39: 75-84.

Alvarez I, Tomaro LM and Benavides PM (2003) Changes in polyamines, proline and ethylene in sunflower calluses treated with NaCl. Plant Cell Tiss. Org. Cult. 74: 51-59.

Arzani A (2008) Improving salinity tolerance in crop plants. A biotechnological view. In Vitro Cell. Dev. Biol. Plant 44: 373-383.

Arzani A and Mirodjagh SS (1999) Response of durum wheat cultivars to immature embryo culture, callus induction and in vitro salt stress. Plant Cell Tiss. Org. Cult. 58: 67-72.

Ashraf M and Foolad MR (2013) Crop breeding for salt tolerance in the era of molecular markers and marker-assisted selection. Plant Breed. 132: 10-20.

Ashraf M and Ahmad S (2000) Influence of sodium chloride an ion accumulation, yield components and fiber characteristics in salt-tolerant and salt-sensitive line of cotton (Gossypium hirsutum L.). Field Crops Res. 66:115-127. 
Bajji M, Lutts S and Kinet JM (2004) Physiological changes after exposure to and recovery from polyethylene glycol-induced water deficit in callus cultures issued from durum wheat (Triticum durum Desf.) cultivars differing in drought resistance. J. Plant Physiol. 156: 75-83.

Baker CM and Dyer WE (1996) Improvements in rooting regenerated safflower (Carthamus tinctorius L.) shoots. Plant Cell Rep. 16: 106-110.

Barakat MN and Abdel-Latif TH (1996) In vitro selection of wheat callus tolerant to high levels of salt and plant regeneration. Euphytica 91:127-140.

Basu S, Gangopadhyay G and Mukherjee BB (2002) Salt tolerance in rice in vitro: Implication of accumulation of $\mathrm{Na}^{+}, \mathrm{K}^{+}$and proline. Plant Cell Tiss. Org. Cult. 96: 5564.

Borsani O, Valpuesta V and Botella MA (2003) Developing salt tolerant plants in a new century: A molecular biology approach. Plant Cell Tiss. Org. Cult. 73: 101-115.

Chawla HS (2000) Introduction to plant biotechnology. Science publisher, New Hampshire ,USA.

Compton ME (1994) Statistical methods suitable for the analysis of plant tissue culture data. Plant Cell Tiss. Org. Cult. 37: 217-242.

Dilek B, Serkan U, Semra M and Ozer K (2008) TDZ x IBA induced shoot regeneration from cotyledonary leaves and in vitro multiplication in safflower (Carthamus tinctorius L.). Afr. J. Biotech. 7: 960-966.

Errabii T, Gandonou CB, Essalmani H, Abrini J, Idaoma M and Senhaji NS (2007) Effects of $\mathrm{NaCl}$ and mannitol induced stress on sugarcane (Saccharum sp.) callus cultures. Acta Physiol. Plant 29: 95-102.

Gandonou C, Abrini J, Idaomar M and Skali Senhaji N (2005) Response of sugarcane (Saccharum sp.) varieties to embryogenic callus induction and in vitro salt stress. Afr. J. Biotechnol. 4: 350-354.

Gawande ND, Mahurkar DG, Rathod TH, Jahagidar SW and Shinde M (2005) In vitro screening of wheat genotypes for drought tolerance. Ann. Plant Physiol. 19: 162-168.

Golkar P, Arzani A and Maibodi SAM (2007). Evaluation of bread wheat (Triticum aestivum L.) cultivars for in vitro salt tolerance. Agric. Sci. Technol. J. 20: 191-200 (In Persian).

Golkar P (2014). Breeding improvements in safflower (Carthamus tinctorius L.): A review. Aust. J. Crop Sci. 8:1079-1085.

Hasan M and Sarker RH (2013) In vitro selection for $\mathrm{NaCl}$ salt tolerance in aromatic rice (Oryza sativa) genotypes. Indian J. Agric. Sci. 83: 1221-1226.

Hasegawa PM (2013) Sodium $\left(\mathrm{Na}^{+}\right)$homeostasis and salt tolerance of plants. Environ. Exp. Bot. 92: 19-31.

Houshmand S, Arzani A, Maibody SAM and Feizi M (2005) Evaluation of salt-tolerant genotypes of durum wheat derived from in vitro and field experiments. Field Crops Res. 91: 345-354.

Karadimova M and Djambova G (1993) Increased $\mathrm{NaCl}$ tolerance in wheat (Triticum aestivum L. and T. durum Desf) through in vitro selection. In Vitro Cell. Dev. Biol. 29: 180-182. 
Khaleda L, Ahmad AMA, Marzan LW and Al-Forkan M (2007) Identification of callus induction and plat regeneration responsiveness in presence of $\mathrm{NaCl}$ in in vitro culture of some deep water rice (Oryza sativa L.) cultivars. Asian J. Plant Sci. 6: 6-41.

Khorami R and Safarnejad A (2011) In vitro selection of Foeniculum vulgare for salt tolerance. Not. Sci. Biol. 3: 90-97.

Knowles PF (1989) Safflower: In Oil Crops of the World. In: Downey RK, Robellen G, Ashri A (ed), McGraw-Hill, New York. pp. 363-374.

Liu TH, Nada K, Handa C, Kitashiba H, Wen XP, Pang XM and Moriguchi T (2006) Polyamine biosynthesis of apple callus under salt stress: importance of arginine decarboxylase pathway in stress response. J. Exp. Bot. 57: 2589-2599.

Lutts S, Kinet JM and Bouharmont J (1999) Improvement of rice callus regeneration in the presence of $\mathrm{NaCl}$. Plant Cell Tiss. Org. Cult. 57: 3-11.

Lutts S, Almansouri M and Kinet JM (2004) Salinity and water stress have contrasting effects on the relationship between growth and cell viability during and after stress exposure in durum wheat callus. Plant Sci. 167: 9-18.

Rafiq M, Mali M, Khatri A and Dahot MU (2008) Callus induction and regeneration in local mungbean (Vigna radiate L. Wilczek) under salt stress. J. Biotechnol. 136: 147-169.

Rai MK, Kalia RK, Manu RS, Gangola P and Dhawan AK (2011) Developing stress tolerant plants through in vitro selection: An overview of the recent progress. Environ. Exp. Bot. 71: 89-98.

Weiss EA (2000) Oil seed Crops. 2nd ed. Blackwell Science, Oxford.

Yan W (2001) GGEbiplot - A windows application for graphical analysis of multienvironment trial data and other types of two-way data. Agron. J. 93: 1111-1118.

Zair A, Chlyah A, Sabounji K, Tittahsen M and Chlyah H (2003) Salt tolerance in some wheat cultivars after application of in vitro pressure. Plant Cell Tiss. Org. Cult. 73: 237-244.

Zebarjadi AR, Ghasempour HR and Soheilikhah Z (2010) Effects of drought stress on biochemical and physiological parameters in callus cultures of Carthamus tinctorius varieties. Acta Agric. Hung. 58: 395-406. 